\title{
MORTALITY AND ITS ASSOCIATED FACTORS IN PATIENTS WITH SPINAL CORD INJURIES AT PARAPLEGIC CENTER PESHAWAR, PAKISTAN
}

\section{Aatik Arsh $^{\otimes 1}$, Haider Darain ${ }^{2}$, Amir Zeb', Syed Muhammad llyas ${ }^{3}$, Shah Khalid ${ }^{4}$}

\begin{abstract}
OBJECTIVE: To determine mortality and its associated factors in patients with spinal cord injuries $(\mathrm{SCl})$, presenting to Paraplegic Center Peshawar, Pakistan.

METHODS: In this retrospective study, clinical records of $\mathrm{SCl}$ patients, admitted to Paraplegic Center from January $201 \mathrm{I}$ to March 2017 were evaluated. $\mathrm{SCl}$ patients who died during this period, irrespective of their age, gender, duration of $\mathrm{SCl}$ and number of readmissions were included in study. Demographic information, clinical characteristic and complications in eligible patients were recorded and analyzed.
\end{abstract}

RESULTS: Out of 62 patients, 46 (74.2\%) were males. Mean age of patients was $4 I .7 \pm 17.3$ years. Twenty-two $(35.5 \%)$ patients aged $\leq 30$ years \& 20 (32\%) patients aged $>50$ years. The most common cause of SCls was fall from height $(n=23,37.1 \%)$, followed by road traffic accident $(n=17,27.4 \%)$ and firearm injury $(n=11,17.7 \%)$. About $51.6 \%$ of patients $(n=32)$ had complete thoracic paraplegia, $30.6 \%(n=19)$ had complete cervical tetraplegia and $8.1 \%$ $(n=5)$ had incomplete cervical tetraplegia. Complications and co-morbid conditions included pressure ulcers $(n=53 ; 85.5 \%)$, limb fractures $(n=7$ II.3\%), deep venous thrombosis $(n=3 ; 4.8 \%)$, hepatitis $(n=2 ; 3.2 \%)$ and injury to brachial plexus $(n=1 ; 1.6 \%)$. Twenty-two (35.5\%) patients underwent spine fixation surgery while forty $(64.5 \%)$ patients were managed conservatively. Majority of the patients $(n=5 I, 82.3 \%)$ died within the first year of SCl.

CONCLUSION: Relatively younger patients were predominant and complete thoracic paraplegia was the commonest $\mathrm{SCl}$ level. Presence of pressure ulcers, limb fractures and deep venous thrombosis in patients with $\mathrm{SCl}$ were major contributing factors to morbidity leading to mortality in our patients.

KEY WORDS: Death (MeSH); Pressure Ulcers (MeSH); Spinal Cord Injuries $(\mathrm{MeSH})$; Rehabilitation (MeSH).

THIS ARTICLE MAY BE CITED AS: Arsh A, Darain H, Zeb A, llyas SM, Khalid S. Mortality and its associated factors in patients with spinal cord injuries at Paraplegic Center Peshawar, Pakistan. Khyber Med Univ J 2019; I I(2):7I-4. DOI: 10.35845/kmuj.2019.1844I

\section{INTRODUCTION}

$S_{s}$ rvival rates amongst patients with spinal cord injury ( $\mathrm{SCl}$ ) have improved in the last few decades, yet mortality of these patients due to certain complications still remains a challenge to health care professionals. ${ }^{1,2}$ $\mathrm{SCl}$ is a life lasting disability which affects almost every organ of body due to which they are prone to developing complications throughout life. ${ }^{3}$ Minor preventable complications such as pressure ulcer (PU), if not prevented and treated timely, can lead to life threatening conditions in such patients. ${ }^{4}$

Despite the large number of studies on
I. Physical Therapist, Physiotherapy Department, Paraplegic Center Peshawar, Pakistan

Email $^{\bowtie}:$ aatikarshkmu@yahoo.com

2. Assistant Professor/Director, Institute of Physical Medicine and Rehabilitation, Khyber Medical University Peshawar, Pakistan

3. Chief Executive Officer, Paraplegic Center Peshawar, Pakistan

4. Student, Physiotherapy Department, Hafeez Institute of Medical Sciences Peshawar, Pakistan.

$\begin{array}{ll}\text { Date Submitted: } & \text { June 12,2018 } \\ \text { Date Revised: } & \text { April 10,2019 } \\ \text { Date Accepted: } & \text { April I2, 2019 }\end{array}$

post $\mathrm{SCl}$ mortality in developed countries, ${ }^{1,2,-9}$ few studies are available regarding mortality of $\mathrm{SCl}$ patients from developing countries. ${ }^{10-13}$ Majority of research studies conducted in developed countries in last two decades reported that causes of death in $\mathrm{SCl}$ patients have changed mostly decreased due to improved medical care and advances in the management protocols. $^{2,7-9}$ Especially, advances in urologic management and skin care decreases death rates caused by $\mathrm{PU}$ and urinary tract infection (UTI). ${ }^{14}$ Respiratory complications and cardiovascular diseases are the most commonly reported causes of death among $\mathrm{SCl}$ patients in developed countries as per recent data..$^{7-9}$ Nevertheless, studies from developing countries reported that infections and septicemia due to UTI and/or PU are still the leading causes of death of such patients in developing countries. ${ }^{10-13}$

The higher incidence of untimely deaths in $\mathrm{SCl}$ patients is reported in developing countries as compared to developed countries. ${ }^{10-13}$ In Pakistan, most of the data available about $\mathrm{SCl}$ patients is limited to demographic information ${ }^{14-18}$ and only a single study has published data on mortality among $\mathrm{SCl}$ patients. ${ }^{19}$ Therefore, the current study was designed to determine mortality and its associated factors in patients with spinal cord injuries. Knowledge of complications of $\mathrm{SCl}$ patients at the time of death will help health care professionals in decision making about management of $\mathrm{SCl}$ patients. Moreover, it will also provide guidance regarding 
TABLE I: AGE DISTRIBUTION AND EDUCATION LEVEL

\begin{tabular}{|c|c|c|c|}
\hline & & $\begin{array}{l}\text { Frequency } \\
\qquad(n=62)\end{array}$ & Percentage \\
\hline \multirow{7}{*}{ Age group } & $<10$ years & $\mathrm{I}$ & 1.6 \\
\hline & II-20 years & 3 & 4.8 \\
\hline & $21-30$ years & 18 & 29 \\
\hline & $31-40$ years & $\mathrm{II}$ & 17.7 \\
\hline & $41-50$ years & 9 & 14.5 \\
\hline & $5 \mathrm{I}-60$ years & 9 & 14.5 \\
\hline & $>60$ years & 11 & 17.7 \\
\hline \multirow{8}{*}{ Education Status } & Uneducated & 35 & 56.5 \\
\hline & Primary & 7 & 11.3 \\
\hline & Middle & 6 & 9.7 \\
\hline & Matric & 7 & 11.3 \\
\hline & Intermediate & 2 & 3.2 \\
\hline & Graduate & 2 & 3.2 \\
\hline & Master & 2 & 3.2 \\
\hline & Ph.D & $\mathrm{I}$ & 1.6 \\
\hline
\end{tabular}

TABLE II: SPINAL CORD INJURY LEVEL OF PATIENTS

\begin{tabular}{|l|c|c|}
\hline Spinal Cord Injury Level & $\begin{array}{c}\text { Frequency } \\
(\mathbf{n = 6 2})\end{array}$ & Percentage \\
\hline Complete cervical tetraplegia & 19 & 30.6 \\
\hline Incomplete cevical tetraplegia & 5 & 8.1 \\
\hline Complete thoracic paraplegia & 32 & $5 \mathrm{I} .6$ \\
\hline Incomplete thoracic paraplegia & 2 & 3.2 \\
\hline Incomplete lumbar paraplegia & 4 & 6.5 \\
\hline
\end{tabular}

TABLE III: COMPLICATION AND CO-MORBIDITIES IN STUDY POPULATION

\begin{tabular}{|l|l|c|c|}
\hline \multicolumn{2}{|l|}{ Complications } & $\begin{array}{c}\text { Frequency } \\
(\mathbf{n = 6 2})\end{array}$ & Percentage \\
\hline \multirow{2}{*}{ Pressure Ulcer } & Single pressure ulcer & 24 & 38.7 \\
\cline { 2 - 4 } & Multiple pressure ulcer & 29 & 46.8 \\
\hline \multirow{2}{*}{ Limb Fracture } & Upper limb & 3 & 4.8 \\
\cline { 2 - 4 } & Lower limb & 4 & 6.5 \\
\hline \multirow{3}{*}{ Others } & Deep venous thrombosis & 3 & 4.8 \\
\cline { 2 - 4 } & Hepatitis & 2 & 3.2 \\
\cline { 2 - 4 } & Brachial Plexus Injury & 1 & 1.6 \\
\hline
\end{tabular}

specific protocols and preventative strategies which should be followed to increase survival of $\mathrm{SCl}$ patients.

\section{METHODS}

This retrospective cross sectional study was conducted in Paraplegic Center Peshawar, Pakistan, in which clinical records of $\mathrm{SCl}$ patients admitted to Paraplegic Center from January 20I I to March 2017 were evaluated.

All those $\mathrm{SCl}$ patients were included in study that died in rehabilitation center, irrespective of their age, gender, duration with $\mathrm{SCl}$, and number of readmissions. The only exclusion criteria were non-traumatic spinal cord injury patients. Sixty-two patients based on inclusion and exclusion criteria were identified, who died in rehabilitation center, their demographic information, clinical characteristic and complications at the time of death were noted and analyzed. Ethical approval was obtained from institutional ethical review committee of Paraplegic Center,
Peshawar. All patients reported in current study were admitted to Paraplegic Center for rehabilitation and/ or pressure ulcer management after their initial treatment/acute management in acute care hospitals.

\section{RESULTS}

Out of 62 patients died during the study period, $46(74.2 \%)$ males and 16 (25.8\%) females. The mean age of the $\mathrm{SCl}$ patients who died in rehabilitation center was $4 \mathrm{I} .7 \pm \mathrm{I} 7.3$ years. Twentytwo $(35.5 \%)$ of patients aged $\leq 30$ years \& $20(32 \%)$ patients aged $>50$ years (Table I). Fifty-four (87.1\%) patients were from Khyber Pakhtunkhwa (KPK), five $(8.1 \%)$ patients were from other provinces of Pakistan while three (4.8\%) patients were from tribal areas.

More than half of patients $(n=43$; $69.4 \%$ ) patients were married while remaining $(n=19 ; 30.6 \%)$ patients were unmarried. All $(n=16 ; 25.8 \%)$ females were housewives, while in male patients $(n=46), 19.4 \%(n=12)$ were farmers, $9.7 \%(n=6)$ were laborer, $37.1 \%(n=23)$ were having other professions while $8.1 \%(n=5)$ were having no profession. In education status, $56.5 \%(n=35)$ patients were uneducated while $43.5 \% \quad(n=27)$ patients were having different level of education (Table I).

The most common cause of $\mathrm{SCl}$ in these patients was fall from height $(n=23$; $37.1 \%$ ), followed by road traffic accident $(n=17 ; 27.4 \%)$ and then fire arm injury $(\mathrm{n}=11 ; 17.7 \%)$ while remaining $(\mathrm{n}=\mathrm{II} ; \mathrm{I} .7 \%)$ patients was having other causes.

Majority of patients $(n=32 ; 51.6 \%)$ were having complete thoracic paraplegia (Table II). Analysis of data regarding complications and co-morbid conditions showed that $85.5 \%(n=53)$ patients were having pressure ulcers while $1 \mathrm{I} .3 \%(\mathrm{n}=7)$ patients were having limb fractures (Table III).

Twenty-two (35.5\%) patients managed through spine fixation surgery while forty $(64.5 \%)$ patients were managed conservatively. Majority of patients died $82.3 \%(n=5 I)$ within the first year of $\mathrm{SCl}$ while remaining $17.7 \%(\mathrm{n}=\mathrm{II})$ patients survived from more than one year. 


\section{DISCUSSION}

This study was focused on determining demographic information and complications of sixty-two $\mathrm{SCl}$ patients who died in rehabilitation center during the study period. Due to retrospective nature of study and incomplete documentation, we were unable to report exact causes of death. The only way to determine causes of death in situations where documentation regarding causes of death is poor is verbal autopsy, ${ }^{20}$ however due to limited resources and quantitative nature of study, current study was not able to apply verbal autopsy.

Results of current study showed that the mean age of the $\mathrm{SCl}$ patients who died in rehabilitation center was $41.7 \pm 17.3$ years. Previous studies conducted in Pakistan regarding $\mathrm{SCl}$ reported lower mean age of $\mathrm{SCl}$ patients, ${ }^{15,16}$ which shows that majority of $\mathrm{SCl}$ patients who died in rehabilitation center tended to be older as compared to $\mathrm{SCl}$ patients admitted to rehabilitation center in Pakistan. In current study, more than half of SCl patients (56.5\%) who died in rehabilitation center were uneducated while previous study from same rehabilitation center reported that $43.0 \%$ of the $\mathrm{SCl}$ patients were uneducated, ${ }^{16}$ which shows that deaths are more common among uneducated $\mathrm{SCl}$ patients. Educated $\mathrm{SCl}$ patients may take extra care to prevent secondary complications, which can be reason for low mortality among educated $\mathrm{SCl}$ patients.

The majority of patients in current study were having complete thoracic paraplegia (51.6\%) followed by complete cervical tetraplegia (30.6\%). Previous studies reported that high neurological level and complete $\mathrm{SCl}$ are associated with increased risk of mortality. ${ }^{2,46-8}$ Similarly, Levy L, et al. ${ }^{12}$ reported that $2 / 3$ of $\mathrm{SCl}$ patients who died within $1^{\text {st }}$ year post injury were tetraplegics while I/3 were paraplegics. However, in current study paraplegic patients were more as compared to tetraplegic patients. The only explanation for this is less admission of tetraplegics to Paraplegic Center, Peshawar that reported to be only $10.8 \% .^{16}$ Though studies from developing countries reported that due to improvement in the management protocols, mortality rate of $\mathrm{SCl}$ patients in $I^{\text {st }}$ year post injury has been decreased in last decades I but still majority of previous studies reported high mortality rates of $\mathrm{SCl}$ patients during the Ist year post injury., ${ }^{4,18}$ In accordance with results of previous studies, current study also reported that majority of patients died (82.3\%) within the first year of $\mathrm{SCl}$.

The most common complication among patients who died in the rehabilitation center was PU. Previous study in same rehabilitation center reported that prevalence of $\mathrm{PU}$ in $\mathrm{SCl}$ patients to be $63.8 \%$ while current study reported that $85.5 \%$ patients were having $\mathrm{PU}$ at time of death. Two major reasons for high prevalence of $\mathrm{PU}$ in $\mathrm{SCl}$ patients reported in previous studies can be that, in most hospitals of Pakistan facilities regarding PU prevention are scarce and that's why majority of $\mathrm{SCl}$ patients develop PU in hospital. Secondly due to lack of awareness in Pakistani society about rehabilitation most patients visit rehabilitation center after developing PU mostly they stay at home. ${ }^{16,21,22}$ Lack of awareness among health care professionals and general population regarding $P U$ prevention and management, inadequate access to health care services, poor hygienic conditions and warm weather are believed to be the additional contributing factors for the development of $\mathrm{PU}$ in $\mathrm{SCl}$ patients of the country. Due to advances in management and skin care, death rates due to PU have been decreased in last two decades, ${ }^{10}$ however, studies from developing countries still has same old high figure of $\mathrm{PU}$ as leading cause of death in $\mathrm{SCl}$ patients. ${ }^{10-13}$

In current study, $4.8 \%$ patients were having DVT at the time of death, while previously $2.7 \%$ prevalence of DVT was reported in $\mathrm{SCl}^{15} \mathrm{DVT}$ and its complications are reported to be the $3^{\text {rd }}$ major cause of death in $\mathrm{SCl}$ survivors. Previous studies reported suicide to be one of the leading cause of death among $\mathrm{SCl}$ patients. ${ }^{2,8,13}$ Though our study as well as other previously conducted studies regarding $\mathrm{SCl}$ failed to report suicide among $\mathrm{SCl}$ patients. Strong religious beliefs, joint family system and support of local community are believed to be the contributing factors for the low rate of suicides among $\mathrm{SCl}$ patients in Pakistan.

The data presented in current study was limited to only those patients who died in rehabilitation center that is why all those patients who died in other hospitals or in homes are missed. Secondly, due to retrospective nature of study and incomplete documentation, exact cause of death was not reported. Regardless of these limitations, current study was unique which reported demographic information and complications of patients with $\mathrm{SCl}$ who died in rehabilitation center.

\section{CONCLUSION}

In our study, relatively younger patients were predominant and complete thoracic paraplegia was the commonest $\mathrm{SCl}$ level. Presence of pressure ulcers, limb fractures and deep venous thrombosis in patients with $\mathrm{SCl}$ were major contributing factors to morbidity leading to mortality in our patients.

\section{REFERENCES}

I. Strauss DJ, DeVivo MJ, Paculdo DR, Shavelle RM. Trends in life expectancy after spinal cord injury. Arch Phys Med Rehabil 2006;87(8):1079-85. DOI:10.1016/j.apmr.2006.04.022.

2. Krause JS, Carter RE, Pickelsimer EE, Wilson D. A prospective study of health and risk of mortality after spinal cord injury. Arch Phys Med Rehabil 2008 ;89 (8) : | 482-9।. DOI:10.1016/j.apmr.2007.II.062.

3. Darain H, Arsh A, Zeb A, llyas SM, Muhammad D, Khan MN. Epidemiology, clinical features and consequences of spinal cord injury in children. J Coll Physicians Surg Pak 20।8;28(7):532-5. DOI: 10.2927I/jcpsp.2018.07.532.

4. O'Connor PJ. Survival after spinal cord injury in Australia. Arch Phys Med Rehabil 2005; 86(I):37-47. DOI:10.1016/j.apmr.2004.03.018.

5. Thietje R, Pouw M, Schulz A, Kienast B, Hirschfeld S. Mortality in patients with traumatic spinal cord injury: descriptive analysis of 62 deceased 
subjects. J Spinal Cord Med 201 I;34(4):482-7.DOI: I0. II79/ 20457723 IIY.0000000022.

6. YeoJD, Walsh J, Rutkowski S, Soden R, Craven M, Middleton J. Mortality following spinal cord injury. Spinal Cord 1998;36(5):329-36. DOI: 10.1038/sj.sc.3100628.

7. Lidal IB, Snekkevik H, Aamodt G, Hjeltnes N, Stanghelle JK, BieringSørensen F. Mortality after spinal cord injury in Norway. J Rehabil Med 2007;39(2):|45-5|. DOI: | 0.2340/ $16501977-0017$.

8. Frankel $\mathrm{H}$, Coll J, Charlifue $\mathrm{S}$, Whiteneck G, Gardner B, Jamous M, et al. Long-term survival in spinal cord injury: a fifty year investigation. Spinal Cord 1998;36(4):266-74. DOI:10.1038/sj.sc.3100638.

9. Hagen EM, Lie SA, Rekand T, Gilhus NE, Gronning M. Mortality after traumatic spinal cord injury: 50 years of follow-up. J Neurol Neurosurg $\begin{array}{lll}\text { Psychiatry 2010;8I (4):368-73. } & \text { (4) }\end{array}$ DOI: I0.1 I36/jnnp. 2009.178798.

10. Oderud T. Surviving spinal cord injury in low income countries. Afr J Disabil 20|4;3(2):80-9. DOI: I0.4|02 /ajod.v3i2.80.

II. Hoque MF, Grangeon C, Reed K. Spinal cord lesions in Bangladesh: an epidemiological study 1994-1995. Spinal Cord 1999;37(I2):8586I.DOI: 10.1038/sj.sc.3100938.

12. Levy L, Makarawo S, Madzivire D, Bhebhe E, Verbeek N, Parry O. Problems, struggles and some success with spinal cord injury in Zimbabwe. Spinal Cord 1998;36(3):213-8. DOI: 10.1038/ sj.sc.3100574.

13. Gosselin R, Coppotelli C. A follow-up study of patients with spinal cord injury in Sierra Leone. Int Orthop $2005 ; 29$ (5):330-2. DOI: 10.1007/s00264-005-0665-3.

14. Michael J, Krause JS, Lammertse DP. Recent trends in mortality and causes of death among persons with spinal cord injury. Arch Phys Med Rehabil 1999;80(1 I): | 41।-9. DOI: 10.1016/S0003-9993(99)90252-6.

15. Arsh A, Darain H, Ilyas SM. Epidemiology and prevalence of deep venous thrombosis in patients with spinal cord injury. Pak J Neurolog Sci 2016; I I (4):22-25.

16. Arsh A, Darain H, llyas SM, Zeb A. Prevelacne of pressure ulcers in patients with spinal cord injury; a retrospective study. Pak J Neurolog Sci 20 I2; I (4): I6-2I.

17. Rathore MFA, Hanif S, Farooq F, Ahmad N, Mansoor SN. Traumatic spinal cord injuries at a tertiary care rehabilitation institute in Pakistan. J Pak Med Assoc 2008;58(2):53-7.

18. Arsh A, Darain H, llyas SM, Zeb A. Consequences of traumatic spinal cord injury during pregnancy in Pakistan. Spinal Cord Ser Cases 2017;3:|704|. DOI: 10.1038/ scsandc.2017.4I.

19. Masood Z, Wardug GM, Ashraf J. Spinal Injuries: Experience of a local neurosurgical centre. Pak J Med Sci 2008;24(3):368-7I.

20. Setel PW, Whiting DR, Hemed Y, Chandramohan D, Wolfson LJ, Alberti $\mathrm{K}$, et al. Validity of verbal autopsy procedures for determining cause of death in Tanzania. Trop Med Int Health 2006; II (5):68I-96. DOI: |0.1||I/j.1365-3156.2006.01603.x.

21. Tauqir SF, Mirza S, Gul S, Ghaffar H, Zafar A. Complications in patients with spinal cord injuries sustained in an earthquake in Northern Pakistan. J Spinal Cord Med 2007; 30:373-7. DOI: 10.1080/10790268.2007.11753 955.

22. Rathore M, Rashid P, Butt A, Malik A, Gill Z, Haig AJ. Epidemiology of spinal cord injuries in the 2005 Pakistan earthquake. Spinal Cord 2007;45(I0):658-63. DOI: 10.1038/ sj.sc.3102023.

\section{AUTHORS' CONTRIBUTIONS}

Following authors have made substantial contributions to the manuscript as under:

AA: Conception and design, drafting the manuscript, final approval of the version to be published

HD: Analysis and interpretation of data, critical revision, final approval of the version to be published

AZ: Acquisition of data, final approval of the version to be published

SMI: Acquisition of data, critical revision, final approval of the version to be published

SK: Data collection, drafting the manuscript, final approval of the version to be published

Authors agree to be accountable for all aspects of the work in ensuring that questions related to the accuracy or integrity of any part of the work are appropriately investigated and resolved.

CONFLICT OF INTEREST
Authors declared no conflict of interest
GRANT SUPPORT AND FINANCIAL DISCLOSURE
NIL

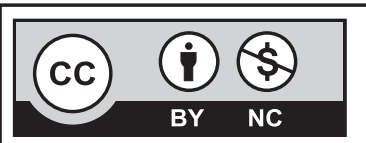

This is an Open Access article distributed under the terms of the Creative Commons Attribution-Non Commercial 2.0 Generic License. 